\title{
KARAKTERISTIK HASIL PENGELASAN PIPA DENGAN BEBERAPA VARIASI ARUS LAS BUSUR LISTRIK
}

\author{
Syaripuddin \\ Teknik Mesin, Fakultas Teknik, Universitas Negeri Jakarta \\ e-mail : syaripuddin_andre@yahoo.com
}

\begin{abstract}
ABSTRAK
Penelitian ini bertujuan untuk mengetahui perbedaan hasil las dan kekuatan sambungan las pada pipa 4" Sch.40 dengan pengujian tarik bahan. Metode yang digunakan dalam penelitian ini adalah metode eksperimen.

Penelitian ini menggunakan pipa 4" schedule 40 bahan baja paduan rendah. Bahan diberi perlakuan pengelasan dengan variasi arus 100 Ampere, 120 Ampere dan 140 Ampere dengan menggunakan las SMAW DC polaritas terbalik dengan elektroda E7016 diameter 3,2 mm. DC polaritas terbalik yaitu pemegang elektroda dihubungkan dengan kutub positif dan logam induk dihubungkan dengan kutub negatif. Jenis kampuh yang digunakan adalah kampuh V dengan sudut $60^{\circ}$. Spesimen dilakukan pengujian tarik.

Kekuatan tarik sambungan las tertinggi terjadi pada kelompok spesimen 140 Ampere yaitu menunjukan tensile rata-rata sebesar $45,796 \mathrm{~kg} / \mathrm{mm}^{2}$ yang mengalami kenaikan sebesar $14,650 \mathrm{Kg} / \mathrm{mm}^{2}$ dari arus 120 Ampere. Kekuatan tarik rata-rata untuk daerah lasan pada kelompok spesimen 100 Ampere yaitu 30,881 Kg/mm² yang mengalami penurunan sebesar $0,377 \mathrm{Kg} / \mathrm{mm}^{2}$ dari kelompok spesimen 120 Ampere yang rata-rata kekuatan tariknya sebesar $31,146 \mathrm{Kg} / \mathrm{mm}^{2}$, dan mengalami penurunan sebesar 14,915 dari arus 140 Ampere.
\end{abstract}

Kata kunci: Arus, Busur Listrik, Kekuatan tarik, E7016.

\section{PENDAHULUAN}

Saluran pipa adalah suatu alat transportasi untuk memindahkan cairan atau gas seperti minyak mentah, air, dan gas alam. Pada hakikatnya pengelasan merupakan penyambungan dua buah logam dengan menggunakan energi panas. Pengembangan teknologi dibidang konstruksi yang semakin maju tidak dapat dipisahkan dari pengelasan karena mempunyai peranan penting dalam rekayasa dan reparasi logam. Pembangunan konstruksi dengan logam pada masa sekarang ini banyak melibatkan metode pengelasan khususnya bidang rancang bangun karena sambungan las merupakan salah satu pembuatan sambungan secara teknis memerlukan keterampilan yang tinggi bagi pengelasnya agar diperoleh sambungan dengan kualitas baik. Lingkup penggunaan teknik pengelasan dalam konstruksi sangat luas meliputi perkapalan, jembatan, sarana transportasi, pipa saluran dan lain sebagainya.

Faktor yang mempengaruhi las adalah prosedur pengelasanya itu suatu perencanaan untuk pelaksanaan penelitian yang meliputi cara pembuatan konstruksi las yang sesuai rencana dan spesifikasi dengan menentukan semuahal yang diperlukan dalam pelaksanaan tersebut. Faktor produksi pengelasan adalah jadwal pembuatan, proses pembuatan, alat dan bahan yang diperlukan, urutan pelaksanaan, persiapan pengelasan, meliputi pemilihan mesin las, penunjukan juru las, pemilihan elektroda, dan penggunaan jenis kampuh.

Mesin las busur listrik menurut arusnya dibedakan menjadi tiga macam yaitu mesin las arus searah atau Direct Current (DC), mesin las arusbolakbalik atau Alternating Current (AC) dan mesin las arus ganda yang merupakan mesin las yang dapat digunakan untuk pengelasan dengan arus searah (DC) dan pengelasan dengan arus bolak-balik (AC). Mesin las yang digunakan untuk penelitian ini adalah mesin las arus searah DC.

Seiring berkembangnya ilmu pengetahuan dan teknologi dalam pengelasan pipa, Laboratorium Las Teknik Mesin Universitas Negeri Jakarta pun terus mengembangkan metode pengelasan tersebut dengan berbagai penelitian salah satunya adalah keberhasilan pembuatan alat bantu putar untuk pengelasan pipa $1 \mathrm{G}$ dengan menggunakan las busur listrik.

Alat bantu putar untuk pengelasan ini sangatlah memiliki manfaat yang sangat baik karena mampu mengelas pipa secara otomatis tanpa memutar pipa secara manual dan dapat diatur kecepatannya sehingga operator pengelas dapat menyesuaikan kecepatan putar pipa dengan pengelasannya agar dapat mencapai pengelasan yang sempurna. Penyetelan kuat arus pengelasan akan mempengaruhi hasil las. Bila arus yang digunakan terlalu rendah akan menyebabkan sukarnya penyalaan busur listrik, dan busur listrik menjadi tidak stabil. Panas yang terjadi tidak cukup untuk 
melelehkan elektroda dan bahan dasar sehingga hasilnya membentuk rigi-rigi las yang kecil dan tidak rata serta penembusan kurang dalam. Sebaliknya bila arus terlalu tinggi maka elektroda akan mencair terlalu cepat dan akan menghasilkan permukaan las yang lebih lebar dan penembusan yang dalam sehingga menghasilkan kekuatan tarik yang rendah dan menambah kerapuhan dari hasil pengelasan. Pada penelitian ini jenis elektroda yang digunakan adalah E7016 dengan diameter 3,2 mm, maka arus yang digunakan berkisar antara 90-165 Ampere. Penentuan besar arus dalam pengelasan ini menggunakan $100 \mathrm{~A}, 120 \mathrm{~A}$, dan $140 \mathrm{~A}$. Kecepatan putar setiap arus disamakan atau konstan. Jenis pipa yang dilas adalah pipa hidrant diameter 4" schedule 40. Posisi yang digunakan pada saat mengelas adalah posisi $1 \mathrm{G}$.

\section{KAJIAN TEORI}

\section{a. Las Busur Listrik}

Las Busur Listrik adalah las busur nyala listrik, adalah pengelasan dengan mempergunakan busur nyala listrik sebagai sumber panas pencair logam. Jenis las ini yang paling lazim dipakai di mana-mana untuk hampir semua keperluan pengelasan.

Untuk keselamatan kerja, maka tegangan yang dipakai hanya 23-45 volt saja, sedangkan untuk pencairan pengelasan dipakai arus listrik hingga 500 amper. Secara umum berkisar antara 80-200 amper.

Untuk mencegah oksidasi (reaksi dengan zat asam $\mathrm{O}_{2}$ ), bahan penambah las (elektroda) dilindungi dengan selapis zat pelindung (fluks atau slag) yang sewaktu pengelasan ikut mencair. Tetapi berhubung berat jenisnya lebih ringan dari bahan metal yang dicairkan, maka cairan fluks tersebut mengapung diatas cairan metal tersebut, sekaligus mengisolasi metal tersebut untuk beroksidasi dengan udara luar, dan sewaktu mendingin/membeku, fluks tersebut juga ikut membeku dan tetap melindungi metal dari reaksi oksidasi. Oksidasi perlu dicegah karena oksidasi metal merupakan senyawa yang tidak mempunyai kekuatan mekanis. [Sriwidharto, 1987]

\section{b. Elektroda Terbungkus}

Elektroda yang habis terpakai maksudnya adalah elektroda yang habis menutupi bahan atau kampuh las dalam proses las dan juga gas yang keluar akibat melelehnya elektroda dan lapisan pelindung digunakan sebagai pelindung saat pengelasan busur. Tujuan lapisan las dilindungi adalah untuk mencegah oksidasi. Lapisan pelindung ini jika sudah mengering akan membentuk terak yang mudah untuk dihilangkan dengan palu atau sikat terak.
Sedangkan bahan yang digunakan untuk melindungi oksidasi berasal dari gas pembakaran busur itu sendiri atau dengan lapisan pelindung kimia dan butiran-butiran zat pelindung oksidasi pada las SAW (Submerged Arc Welding).

Adapun lapisan-lapisan tersebut terdiri dari beberapa jenis yang disesuaikan dengan maksud dan cara pelindungan yang tepat untuk berbagai jenis pengelasan. Jenis-jenis pelindung yang dimaksud antara lain ;

1. High cellulose sodium.

2. High cellulose potassium.

3. Low hydrogen sodium.

4. Low hydrogen potasium.

5. Iron powder, low hydrogen.

6. High iron oxide.

7. High iron oxide, iron powder.

8. High titania potassium.

9. Iron powder, titania.

10. High tittania sodium.

11. Low hydrogen potassium, iron powder.

Pengelasan dengan menggunakan las busur listrik memerlukan kawat las (elektroda) yang terdiri dari satu inti terbuat dari logam yang dilapisi lapisan dari campuran kimia. Fungsi dari elektroda sebagai pembangkit dan sebagai bahan tambah. Elektroda terdiri dari dua bagian yaitu bagian yang berselaput (fluks) dan tidak berselaput yang merupakan pangkal untuk menjepitkan tang las. Fungsi dari fluks adalah untuk melindungi logam cair dari lingkungan udara, menghasilkan gas pelindung, menstabilkan busur.

Menurut AWS (American Welding Society) elektroda diklasifikasikan dengan huruf $\mathrm{E}$ dan diikuti empat atau lima digit sebagai berikut E xxxx (x).

Dua digit yang pertama atau tiga digit menunjukan kuat tarik hasil las tiga digit menunjukan kuat tarik lebih dari 100.000 psi sedangkan dua digit menunjukan kuat tarik hasil lasan kurang dari 100.000psi. sebagai contoh elektroda E 7016 mempunyai kuat tarik 70.000 psi $\left(42 \mathrm{Kg} / \mathrm{mm}^{2}\right)$. Sedangkan adigit selanjutnya menunjukan posisi pengelasan, apabila 1 berarti untuk segala posisi pengelasan, angka 2 berarti las datar atau horizontal dan angka 3 menunjukan pengelasan datar saja. Digit yang terakir menunjukan jenis dari campuran kimia dari lapisan elektroda.

\section{c. Polaritas}

Mesin las DC dapat digunakan dengan dua cara yaitu polaritas lurus dan polaritas terbalik. Mesin las DC polaritas lurus (DC-) digunakan bila titik cair bahan induk tinggi dan kapasitas besar, untuk pemegang elektrodannya 
dihubungkan dengan kutub negatif dan logam induk dihubungkan dengan kutub negatif dan logam induk digunakan dengan kutub positif, pada polaritas jenis ini panas yang diterima adalah $30 \%$ pada elektroda dan $70 \%$ pada benda kerja. Sedangkan untuk mesin las DC polaritas terbalik (DC+) digunakan bila titik cair bahan induk rendah dan kapasitas kecil, untuk pemegang elektrodanya dihubungkan dengan kutub positif dan logam induk dihubungkan dengan kutub negatif.

Pada jenis polaritas ini panas yang diterima benda kerja adalah 30\% dan pada elektroda $70 \%$ sehingga penembusan zat cairan las lebih dalam. Pemilihan ketika menggunakan DC polaritas negatif atau positif adalah terutama ditentukan elektroda yang digunakan. Beberapa elektroda SMAW didisain untuk digunakan hanya DC- atau DC+. Elektroda ini dapat menggunakan keduannya.

\section{d. Besar Arus Listrik}

Besar arus pada pengelasan mempengaruhi hasil lasan. Bila arus terlalu rendah akan mempersulit penyalaan busur listrik dan busur listrik yang terjadi tidak stabil. Panas yang terjadi tidak cukup untuk melelehkan elektroda dan bahan dasar sehingga hasilnya merupakan rigi-rigi las yang kecil dan tidak rata dan penembusan kurang dalam.

Sebaliknya bila arus terlalu besar, elektroda akan mencair terlalu cepat dan menghasilkan permukaan las yang lebih lebar dan penembusan yang dalam. Besar arus pengelasan tergantung jenis kawat las yang dipakai.

Besarnya arus listrik untuk pengelasan tergantung pada ukuran diameter dan macam elektroda las.[Siswanto, 2011] Jadi, besarnya arus pengelasan yang diperlukan tergantung pada diameter elektroda, tebal bahan yang dilas, jenis elektroda yang digunakan, diameter inti elektroda, dan posisi pengelasan.

\section{e. Jenis Kampuh Las}

Kampuh las berguna untuk difusi antara logam induk dan logam las terjadi ikatan metalurgi yang sempurna. Sedangkan jenis kampuh las yang dipakai pada tiap pengelasan tergantung pada:

1. Ketebalan benda kerja.

2. Jenis benda kerja.

3. Kekuatan yang diinginkan.

4. Posisi pengelasan.

Dan jenis kampuh diantaranya :

1. Kampuh I
2. Kampuh $\mathrm{K}$

3. Kampuh V

4. Kampuh U

5. Kampuh $\mathrm{T}$

6. Kampuh X

7. Kampuh J

\section{f. Daerah Pengaruh Panas}

Proses pengelasan melibatkan pemanasan dan pendinginan, pada umumnya struktur mikro dari logam tergantung dari kecepatan pendinginannya dari temperatur terbentuknya fasa awal sampai ke temperature kamar. Karena perubahan struktur ini dengan sendirinya sifat-sifat mekanik yang dimiliki juga berubah. Pada dasarnya daerah pengelasan terdiri dari 3 bagian yaitu logam lasan, daerah pengaruh panas (HAZ) dan logam induk tidak terpengaruh panas. Logam las adalah bagian dari logam yang pada waktu pengelasan mencair kemudian membeku. Daerah pengaruh panas atau daerah HAZ adalah logam dasar yang bersebelahan dengan logam las yang selama proses pengelasan mengalami siklus termal pemanasan dan pendinginan cepat. Logam induk tak terpengaruhi panas adalah logam yang selama proses pengelasan tidak terjadinya struktur dan sifat. [Harsono, 1996]

\section{g. Metode DT}

Metode DT (Destructive Test) adalah pengujian terhadap model dari kontruksi atau pada batang-batang uji yang telah dilas dengan cara yang sama dengan proses pengelasan yang akan digunakan sampai terjadi kerusakan pada model kontruksi atau batang uji. [Harsono, 1996]

\section{Uji Tarik}

Uji tarik dipakai untuk mengukur beban tarik maksimum (hingga putus) yang mampu didukung oleh lasan. Hasil uji lasan dibandingkan dengan kekuatan tarik benda kerja sebelum dilas sehingga bisa diketahui bila ada perubahan karena pengaruh pengelasan. [M. Alip, 1989]

Uji tarik dilaksanakan untuk menentukan kekuatan tarik, titik mulur (kekuatan lentur) las, pemanjangan dan pengurangan material las. Spesimen tersebut ujung-ujungnya dipegang dengan jepitan alat penguji, dan ditarik dengan menggunakan beban tarik.

\section{Uji Kekerasan}

Lasan sering juga diuji tingkat kekerasannya untuk mengevaluasi ada tidak pengaruh panas terhadap kekerasannya. Kekerasan lasan diukur sebagai kontrol properties bahan setelah dilas dan sering 
dihubungkan dengan kekuatan tarik atau ductility atau properties lain. Uji kekerasan lasan sering dilakukan bila lasan harus dikerjakan lagi, atau merupakan lasan penebalan pada bagian yang sering aus, misal poros. [M. Alip, 1989]

\section{METODOLOGI PENELITIAN}

\section{a. Metode Penelitian}

Metode yang dipergunakan oleh penulis dalam penelitian ini agar dapat dipertanggung jawabkan adalah Metode eksperimen. Eksperimen dilaksanakan di laboratorium dengan kondisi dan peralatan yang diselesaikan guna memperoleh data tentang pengaruh arus pengelasan terhadap teknik pengujian tarik las busur listrik dengan elektroda E7016. Adapun spesifikasi benda uji adalah sebagai berikut:

1. Bahan yang digunakan adalah pipa 4" schedule 40

2. Diameter dalam pipa $6 \mathrm{~mm}$.

3. Elektroda yang digunakan adalah E7016 dengan diameter 3,2 mm.

4. Posisi pengelasan dengan menggunakan posisi bawah tangan.

5. Arus pengelasan adalah $100 \mathrm{~A}, 120 \mathrm{~A}$, dan 140 A.

6. Kampuh yang digunakan adalah kampuh $\mathrm{V}$ dengan sudut $60^{\circ}$, celah antar pipa 2 $\mathrm{mm}$, dan tinggi akar $2 \mathrm{~mm}$.

7. Bentuk spesimen benda uji mengacu pada standar Badan Standardisasi Nasional (BSN) No.12 A untuk pengujian tarik.

Tabel 3.1 Standarisasi Bentuk Spesimen Uji Tarik Menurut BSN

Pengelompok1 batang ul sesual bentuk produk

\begin{tabular}{|c|c|c|c|c|}
\hline \multicolumn{2}{|c|}{ Produk } & \multicolumn{2}{|c|}{ Batang uy } & \multirow[t]{2}{*}{ Keterangan } \\
\hline Bentuk & Ukuran & Proporsional & $\begin{array}{l}\text { Tldak } \\
\text { proporsional }\end{array}$ & \\
\hline \multirow{7}{*}{$\begin{array}{l}\text { Pelat, } \\
\text { lembaran } \\
\text { strip }\end{array}$} & \multirow{2}{*}{$\begin{array}{l}\text { Tebal dlatas } \\
40 \mathrm{~mm}\end{array}$} & No. $14 \mathrm{~A}$ & No. 4 , No. 10 & Eentuk batang \\
\hline & & No. $14 \mathrm{~B}$ & - & Bentuk pipin \\
\hline & \multirow{2}{*}{$\begin{array}{l}\text { Tebal d dlatas } \\
20 \mathrm{~s} / \mathrm{d} 40 \mathrm{~mm} \\
\end{array}$} & No. $14 \mathrm{~A}$ & No. 4 , No. $1 \mathrm{C}$ & Bentuk batang \\
\hline & & No. $14 \mathrm{~B}$ & No. $1 \mathrm{~A}$ & \multirow{4}{*}{ Bentuk plpin } \\
\hline & $\begin{array}{l}\text { Tebal dlatas } \\
6 \text { s/d } 20 \mathrm{~mm}\end{array}$ & & $\begin{array}{l}\text { No. } 1 \text { A } \\
\text { No. } 5\end{array}$ & \\
\hline & $\begin{array}{l}\text { Tebal datatas } \\
3 \mathrm{sid} 6 \mathrm{~mm}\end{array}$ & NNo. 148 & \multirow[t]{2}{*}{$\begin{array}{l}\text { No. } 5 \\
\text { No. } 13 \text { A } \\
\text { No. } 13 \text { B }\end{array}$} & \\
\hline & Tebal s:d 3 & 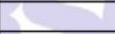 & & \\
\hline Batang & & $\begin{array}{l}\text { No. } 2 \\
\text { No. } 14 \mathrm{~A}\end{array}$ & $\begin{array}{l}\text { No. } 4 \\
\text { No. } 10\end{array}$ & \\
\hline Kawat & & & $\begin{array}{l}\text { No. } 9 \mathrm{~A} \\
\text { No. } 9 \mathrm{~B}\end{array}$ & \\
\hline \multirow{6}{*}{ PIpa } & $\begin{array}{l}\text { Dla. Iuar } \\
\text { Plpa kecll }\end{array}$ & & No. 11 & Bentuk tabung \\
\hline & $\begin{array}{l}\text { Dla. luar } \\
\text { Sampal } 50 \mathrm{~mm}\end{array}$ & & No. $12 \mathrm{~A}$ & \multirow{3}{*}{$\begin{array}{l}\text { Bentuk } \\
\text { Penampang } \\
\text { Busur }\end{array}$} \\
\hline & $\begin{array}{l}\text { Dla luar } \\
\text { diatas } 50 \mathrm{~mm} \\
\text { sid } 170 \mathrm{~mm}\end{array}$ & & No. $12 \mathrm{~B}$ & \\
\hline & $\begin{array}{l}\text { Dla. luar } \\
\text { dilatas } 170 \mathrm{~mm} \\
\end{array}$ & & No. $12 \mathrm{C}$ & \\
\hline & $\begin{array}{l}\text { Dia. luar } \\
\text { dilatas } 200 \mathrm{~mm}\end{array}$ & & No. 5 & Bentuk datar \\
\hline & $\begin{array}{l}\text { Pipa dinding } \\
\text { tebal }\end{array}$ & & No. 4 & Bentuk Datang \\
\hline
\end{tabular}

Tabel 3.2 Spesifikasi Pengujian Tarik Untuk Spesimen Pipa

\begin{tabular}{|c|c|c|c|c|c|}
\hline \multicolumn{6}{|c|}{ Ukuran batang uji no. 12} \\
\hline \multicolumn{6}{|r|}{ Satuan : $m m$} \\
\hline Nomor & Lebar & Panjang & Panjang & Jari-jari & Tebal \\
\hline batang & & ukur & paralel & bahu & \\
\hline & W & & & & T \\
\hline $12 \mathrm{~A}$ & 19 & 50 & Lebih & $\min .1 .5$ & sesuai tebal \\
\hline & & & kurang 60 & & pipa \\
\hline $12 \mathrm{~B}$ & 25 & 50 & Lebih & $\min .15$ & sesuai tebal \\
\hline & & & kurang 60 & & \\
\hline $12 \mathrm{C}$ & 38 & 50 & Lebih & $\min .15$ & sesuai tebal \\
\hline & & & kurang 60 & & pipa \\
\hline
\end{tabular}

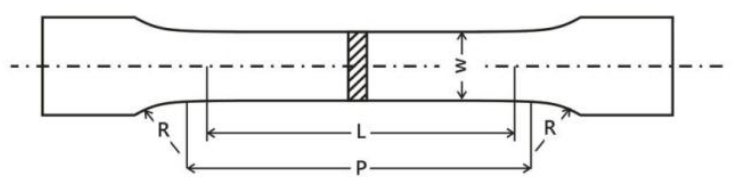

Gambar 3.1 Bentuk Spesimen Uji Tarik

Tabel 3.3 Ukuran Spesimen Uji Tarik 12 A

\begin{tabular}{|c|c|c|c|l|}
\hline $\begin{array}{c}\text { Lebar } \\
(\mathrm{W})\end{array}$ & $\begin{array}{c}\text { Panjang } \\
(\text { Lo })\end{array}$ & $\begin{array}{c}\text { Panjang parallel } \\
(\mathrm{P})\end{array}$ & $\begin{array}{c}\text { Jari-jari bahu } \\
(\mathrm{R})\end{array}$ & $\begin{array}{c}\text { Tebal } \\
(\mathrm{T})\end{array}$ \\
\hline $19 \mathrm{~mm}$ & $50 \mathrm{~mm}$ & $60 \mathrm{~mm}$ & $15^{\circ}$ & $\begin{array}{l}\text { Sesuai tebal } \\
\text { pipa }\end{array}$ \\
\hline
\end{tabular}

\section{b. Alur Kerja Penelitian}

Alur kerja yang akan dilakukan adalah sebagai berikut :

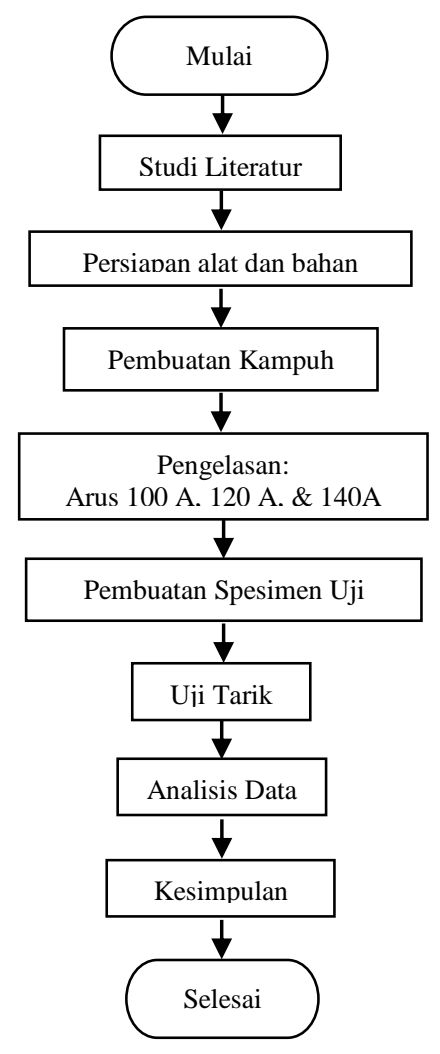

Gambar 3.2. Alur Kerja Penelitian 


\section{HASIL DAN PEMBAHASAN}

Pengujian tarik dilakukan untuk mengetahui sifat-sifat mekanis dari material baja paduan rendah sebagai material uji dalam penelitian ini. Hasil pengujian tarik pada umumnya adalah parameter kekuatan (kekuatan tarik dan kekuatan luluh), parameter keuletan yang ditunjukkan dengan adanya persentase perpanjangan dan persentase kontraksi atau reduksi penampang. Pengujian tarik dengan menggunakan mesin pada skala beban 10 ton. Spesimen pengujian terdiri dari pengujian tarik untuk kualitas kekuatan tarik pipa paduan hydrogen rendah hasil pengelasan SMAW dengan elektroda E7016. Data-data hasil pengujian tarik pada kelompok variasi arus pengelasan yang sudah diperoleh kemudian dimasukkan kedalam persamaan yang ada.

\section{a. Hasil Uji Tarik Pengelasan Pada Arus 100 A.}

Data hasil pengujian tarik pada kelompok 1 yang sudah diperoleh kemudian dimaksukkan kedalam tabel. Data tersebut selanjutnya dapat dilihat dari Tabel 4.1

Tabel 4.1 Hasil Uji Tarik Kelompok 1

\begin{tabular}{|c|c|c|c|}
\hline Arus & $\begin{array}{c}\text { No. } \\
\text { Sampel }\end{array}$ & $\begin{array}{c}\text { Tensile } \\
\text { Strenght } \\
\left(\mathrm{Kg} / \mathrm{mm}^{2}\right)\end{array}$ & $\begin{array}{l}\text { Rata-rata } \\
\left(\mathrm{Kg} / \mathrm{mm}^{2}\right)\end{array}$ \\
\hline \multirow{3}{*}{$100 \mathrm{~A}$} & 1 & 30,881 & \multirow{3}{*}{30,769} \\
\hline & 2 & 29,124 & \\
\hline & 3 & 32,304 & \\
\hline
\end{tabular}

Data dari tabel 4.1 hasil pengujian tarik kelompok 1 selanjutnya dimasukkan kedalam diagram batang seperti dibawah ini :

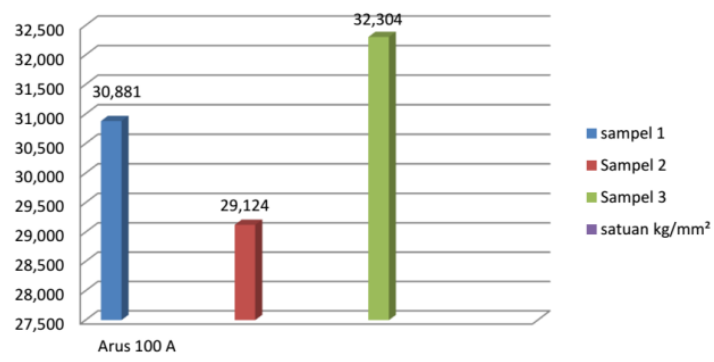

Gambar 4.1 Diagram Hasil Uji Tarik Kelompok 1

Nilai kekuatan tarik untuk arus 100 A no. 1 adalah $30,881 \mathrm{Kg} / \mathrm{mm}^{2}$. Nilai kekuatan tarik untuk no.2 adalah $29,124 \mathrm{Kg} / \mathrm{mm}^{2}$. Nilai kekuatan tarik untuk no.3 adalah 32,304 $\mathrm{Kg} / \mathrm{mm}^{2}$. Nilai rata-rata kekuatan tarik untuk kelompok arus $120 \mathrm{~A}$ sebesar $29,887 \mathrm{Kg} / \mathrm{mm}^{2}$.

\section{b. Hasil uji Tarik pengelasan pada arus $120 \mathrm{~A}$.}

Data hasil pengujian tarik pada kelompok 2 yang sudah diperoleh kemudian dimaksukkan kedalam tabel. Data tersebut selanjutnya dapat dilihat dari Tabel 4.2.

Tabel 4.2 Hasil Uji Tarik Kelompok 2

\begin{tabular}{|c|c|c|c|}
\hline Arus & $\begin{array}{c}\text { No. } \\
\text { Sampel }\end{array}$ & $\begin{array}{c}\text { Tensile } \\
\text { Strenght } \\
\left(\mathbf{K g} / \mathbf{m m}^{2}\right)\end{array}$ & $\begin{array}{c}\text { Rata-rata } \\
\left(\mathbf{K g} / \mathbf{m m}^{2}\right)\end{array}$ \\
\hline \multirow{2}{*}{ 120 A } & 1 & 32,159 & \multirow{2}{*}{31,146} \\
\cline { 2 - 3 } & 2 & 31,783 & \multirow{2}{*}{} \\
\cline { 2 - 3 } & 3 & 29,497 & \\
\hline
\end{tabular}

Data dari tabel 4.2 hasil pengujian tarik kelompok 2 selanjutnya dimasukkan kedalam diagram batang seperti dibawah ini :

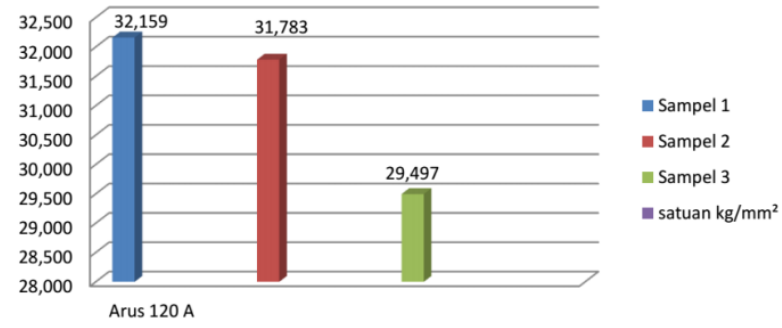

Gambar 4.2 Diagram Hasil Uji Tarik Kelompok 2

Nilai kekuatan tarik untuk arus 120 A no. 1 adalah $32.159 \mathrm{Kg} / \mathrm{mm}^{2}$. Nilai kekuatan tarik untuk no. 2 adalah $31.783 \mathrm{Kg} / \mathrm{mm}^{2}$. Nilai kekuatan tarik untuk no.3 adalah 29.497 $\mathrm{Kg} / \mathrm{mm}^{2}$. Nilai rata-rata kekuatan tarik untuk kelompok arus 120A sebesar $31.146 \mathrm{Kg} / \mathrm{mm}^{2}$.

\section{c. Hasil uji Tarik pengelasan pada arus $140 \mathrm{~A}$.}

Data hasil pengujian tarik pada kelompok 3 yang sudah diperoleh kemudian dimaksukkan kedalam tabel. Data tersebut selanjutnya dapat dilihat dari Tabel 4.3.

Tabel 4.3 Hasil Uji Tarik Kelompok 3

\begin{tabular}{|c|c|c|c|}
\hline Arus & $\begin{array}{c}\text { No. } \\
\text { Sampel }\end{array}$ & $\begin{array}{c}\text { Tensile } \\
\text { Strenght } \\
\left(\mathbf{K g} / \mathbf{m m}^{2}\right)\end{array}$ & \multirow{2}{*}{$\begin{array}{c}\text { Rata-rata } \\
\left(\mathbf{K g} / \mathbf{m m}^{2}\right)\end{array}$} \\
\hline \multirow{3}{*}{ 140 A } & 1 & 48,748 & \multirow{2}{*}{45,796} \\
\cline { 2 - 3 } & 2 & 53,188 & \multirow{2}{*}{} \\
\cline { 2 - 3 } & 3 & 35,453 & \\
\hline
\end{tabular}

Data dari tabel 4.3 hasil pengujian tarik kelompok 3 selanjutnya dimasukkan kedalam diagram batang seperti dibawah ini :

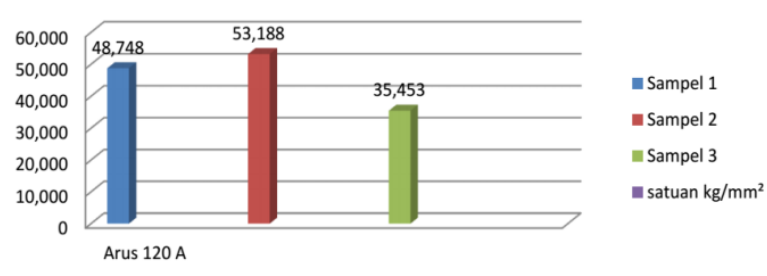

Gambar 4.3 Diagram Hasil Uji Tarik Kelompok 3 
Nilai kekuatan tarik untuk arus 140 A kelompok 3 sampel no.1 adalah 48.748 $\mathrm{Kg} / \mathrm{mm}^{2}$. Nilai kekuatan tarik untuk sampel no. 2 adalah $53,188 \mathrm{Kg} / \mathrm{mm}^{2}$. Nilai kekuatan tarik untuk sampel no. 3 adalah $35.453 \mathrm{Kg} / \mathrm{mm}^{2}$. Nilai rata-rata kekuatan tarik untuk kelompok arus 140 A sebesar 45,796 Kg/mm².

Tabel 4.4 Hasil Rekapitulasi Keseluruhan Uji Tarik

\begin{tabular}{|c|c|c|c|}
\hline Arus & $\begin{array}{c}\text { No. } \\
\text { Sampel }\end{array}$ & $\begin{array}{c}\text { Tensile } \\
\text { Strenght } \\
\left(\mathrm{Kg} / \mathrm{mm}^{2}\right)\end{array}$ & $\begin{array}{l}\text { Rata-rata } \\
\left(\mathrm{Kg} / \mathrm{mm}^{2}\right)\end{array}$ \\
\hline \multirow{3}{*}{$100 \mathrm{~A}$} & 1 & 30,881 & \multirow{3}{*}{30,769} \\
\hline & 2 & 29,124 & \\
\hline & 3 & 32,304 & \\
\hline \multirow{3}{*}{$120 \mathrm{~A}$} & 1 & 32,159 & \multirow{3}{*}{31,146} \\
\hline & 2 & 31,783 & \\
\hline & 3 & 29,497 & \\
\hline \multirow{3}{*}{$140 \mathrm{~A}$} & 1 & 48,748 & \multirow{3}{*}{45,796} \\
\hline & 2 & 53,188 & \\
\hline & 3 & 35,453 & \\
\hline
\end{tabular}

Data dari tabel 4.4 hasil rekapitulasi pengujian tarik selanjutnya dimasukkan kedalam diagram batang seperti dibawah ini :

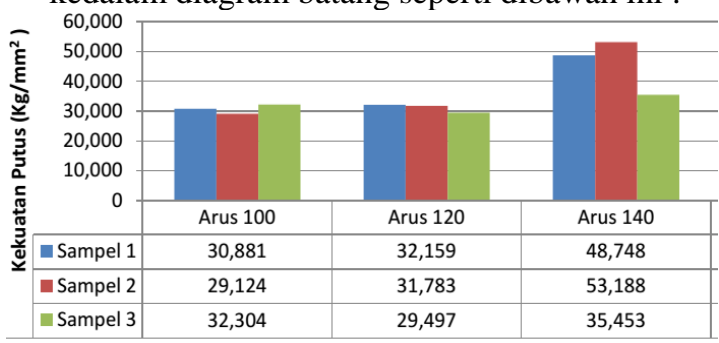

Gambar 4.4 Hasil Rekapitulasi Uji Tarik

Data dari tabel 4.4 hasil rekapitulasi pengujian tarik selanjutnya diambil hasil ratarata uji Tarik pada setiap kelompok dan dimasukkan kedalam diagram batang seperti dibawah ini :

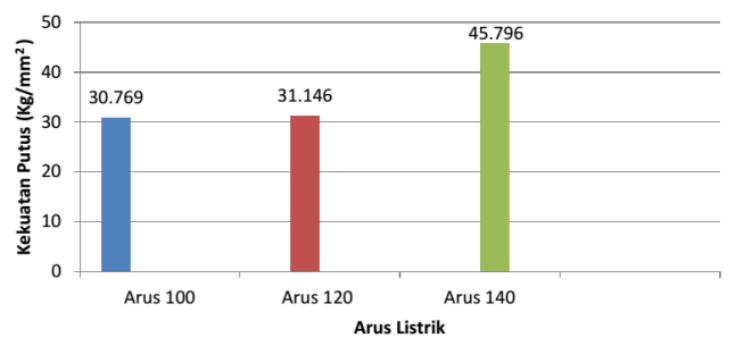

Gambar 4.5 Hasil Rata-Rata Uji Tarik

Nilai kekuatan tarik untuk arus $100 \mathrm{~A}$ adalah $30,769 \mathrm{Kg} / \mathrm{mm}^{2}$. Nilai kekuatan tarik untuk arus $120 \mathrm{~A}$ adalah $31.146 \mathrm{Kg} / \mathrm{mm}^{2}$, ini berarti mengalami kenaikan sebesar 0.377 $\mathrm{Kg} / \mathrm{mm}^{2}$ dari arus $100 \mathrm{~A}$. Nilai kekuatan tarik untuk arus $140 \mathrm{~A}$ adalah $45,796 \mathrm{Kg} / \mathrm{mm}^{2}$, hal ini berarti mengalami kenaikan sebesar 14,650 $\mathrm{Kg} / \mathrm{mm}^{2}$ dari arus $120 \mathrm{~A}$ dan sebesar 15,027 $\mathrm{Kg} / \mathrm{mm}^{2}$ dari arus $100 \mathrm{~A}$.

\section{KESIMPULAN}

Berdasarkan data yang diperoleh, maka kesimpulan dari penelitian ini adalah:

1. Nilai kekuatan tarik untuk arus $100 \mathrm{~A}$ kampuh V $60^{\circ}$ adalah $30,746 \mathrm{Kg} / \mathrm{mm}^{2} .2$

2. Nilai kekuatan tarik untuk arus $120 \mathrm{~A}$ kampuh V $60^{\circ}$ adalah $31,146 \mathrm{Kg} / \mathrm{mm}^{2}$.

3. Nilai kekuatan tarik untuk arus 140 A kampuh V $60^{\circ}$ adalah $45,796 \mathrm{Kg} / \mathrm{mm}^{2}$.

4. Berdasarkan data diatas dapat diketahui bahwa nilai kekuatan tarik yang paling besar terdapat pada arus 140 A kampuh V $60^{\circ}$.

\section{REFERENSI}

Alip, Mochamad. Teori dan Praktek Las. Jakarta: F.P.T.K. IKIP Yogyakarta. 1989.

Amstead, B. H. dkk. Teknologi Mekanik, Jakarta: Erlangga. 1997.

Katarman, Maman. Fabrikasi Komposit, Jakarta: FT-UI. 2010

Kenyon, W. Dasar-dasar Pengelasan, Jakarta: Erlangga. 1985.

Siswanto dan Amri, Saufan. Konsep Dasar Teknik Las, Jakarta: Prestasi Pustaka. 2011.

Sunaryo, Hery. Teknik Pengelasan Kapal, Jakarta: Direktorat Pembinaan Sekolah Kejuruan. 2009.

Sriwidharto. Petunjuk Kerja Las, Jakarta: Pradnya Paramita. 2009.

Sriwidharto. Inspeksi Teknik Buku 1, Jakarta: Pradnya Paramita. 2009.

Wiryosumarto, Harsono dan Okumura, Toshie. Teknologi Pengelasan Logam, Jakarta: Pradnya Paramita. 1996. 